\title{
Avaliação do potencial de fermentação metanogênica da Eichhornia crassipes (aguapé)
}

\author{
Evaluation the potential methanogenic fermentation \\ of Eichhornia crassipes (hyacinth)
}

Francyelly Giovany Cordeiro | Angélica Christina Melo Nunes Astolfi

Data de entrada: 01/02/2012 | Data de aprovação: 03/09/2012

Resumo

Em milhões de anos o consumo de energia cresceu espantosamente, ocasionando o uso excessivo dos combustíveis fósseis, que resultou não só na poluição do ar e no aceleramento do efeito estufa, mas também na exaustão das reservas petrolíferas, tornando a questão energética um grande desafio para a humanidade. Neste sentido, o presente trabalho contém estudos que avaliam a potencialidade do uso da E. crassipes como substrato de metanização para obtenção de energia renovável. O estudo utilizou meios de reação triturado e fluidizado, compostos por diferentes substratos. De acordo com os dados obtidos, o meio indicado como ideal para a biodigestão é o composto por aguapé triturado, serragem, 25\% de inóculo e bicarbonato, alcançando a eficiência das bactérias metanogênicas e conduzindo a formação de biogás contendo 80,76\% de metano, com rendimento em biogás de $6,90 \mathrm{~cm}^{3} / \mathrm{g}$ de substrato.

Palavras-chave: Energia; Biogás; Eichhornia Crassipes; Fermentação Metanogênica.

\begin{abstract}
In millions of years the energy consumption has grown remarkably, resulting in the excessive use of fossil fuels, which not only resulted in air pollution and accelerating the greenhouse effect, but also in the depletion of oil reserves, making the energetic issue a major challenge for humanity. In this sense, the present work contains studies that evaluate the potentiality of the use of E. crassipes as methanisation substrate for obtaining renewable energy. The study used reaction fields crushed and fluidized, composed by different substrates. According to the data obtained, the field indicated as the ideal for biodigestion is the composed by crushed water hyacinth, sawdust, 25\% of inoculum and bicarbonate, reaching the efficiency of the methanogenic bacterias and leading to the formation of biogas containing $80.76 \%$ of methane, with biogas yield of $6.90 \mathrm{~cm}^{3} / \mathrm{g}$ of substrate.
\end{abstract}

Key-words: Energy; Biogas; Eichhornia Crassipes; Methanogenic Fermentation.

\footnotetext{
Francyelly Giovany Cordeiro*

Engenheira Ambiental pelo Centro Universitário de Lins, pós- graduanda em Engenharia de Segurança do Trabalho pelo Centro Universitário de Lins e mestranda em Engenharia Civil e Ambiental pela UNESP de Bauru. E-mail: fran.g.cordeiro@gmail.com Angélica Christina Melo Nunes Astolfi

Engenheira Ambiental pelo Centro Universitário de Lins. E-mail: angelchrismelo@gmail.com
}

* Endereço para correspondência: Rua Benjamim Hadba, n. 520, Centro - Iacanga (SP), CEP: 17180-000. E-mail: fran.g.cordeiro@gmail.com 


\section{Introdução}

Após a Revolução Industrial, os modelos de consumo de energia vieram tomando forma e se tornando insustentáveis diante principalmente da degradação ambiental e da saúde humana. Segundo dados do caderno de informações de saúde, cerca de 2,4 milhões de pessoas morrem anualmente devido a causas diretamente relacionadas à poluição do ar (MINISTÉRIO DA SAÚDE; IBGE, 2010).

Dados divulgados por especialistas revelam que estamos caminhando para o esgotamento destas reservas petroliferas. Em uma entrevista para o jornal britânico The Independent, o economista chefe da Agência Internacional de Energia (IEA), Fatih Birol, fez um alerta sobre as reservas de petróleo, ele afirmou que a produção mundial deverá atingir o pico em cerca de 10 anos, pelo menos uma década mais cedo do que a maioria dos governos havia estimado (CONNOR, 2009).

Apesar de tudo, de acordo com levantamentos feitos pelo MME; EPE (2010), a matriz energética mundial ainda é predominantemente fóssil, apenas $29,5 \%$ do consumo final mundial são de fontes renováveis, o que gera emissões de poluentes locais, gases de efeito estufa e põem em risco o suprimento de longo prazo no planeta.

Já o Brasil possui características geográficas e hidrológicas favoráveis, assegurando que quase $80 \%$ da oferta interna de energia elétrica seja hidráulica, considerada "energia limpa", no entanto, com a crise energética vivenciada pelo Brasil em 2001 e 2002, observou-se que o país é dependente das condições climáticas, causando limitações na produção e no desenvolvimento econômico, sendo necessário sua diversificação.

Em vista do exposto, a questão energética se tornou um grande desafio para a humanidade, e para solucionar os mesmos as fontes renováveis de energia vêm sendo pesquisadas.

Em meio às possibilidades para se gerar eletricidade a partir de fontes renováveis tem-se a E. crassipes, que se sobressai dentre às diversas fontes de biomassa devido sua enorme velocidade de crescimento (MUKUNO, et al., 1995).

Wolverton; Mcdonald (1979) afirmam que a Eichhornia crassipes é uma planta que apresenta uma produtividade elevadíssima, podendo atingir 360 a 480 t/ha.ano, conferindo a ela a feição de praga aquática, causando problemas em rios, reservatórios de usinas hidrelétricas e reservatórios de água para irrigação.
Além disso, o aguapé tem a capacidade de absorver em seus tecidos elevadas quantidades de nutrientes, o que torna interessante sua utilização como agente despoluidor de águas (KNIPLING, et al., 1970), conferindo a essa biomassa um custo nulo de produção. Tornando assim interessante o seu aproveitamento como matéria-prima para a metanização.

Neste sentido, o presente estudo tem como objetivo avaliar a possibilidade do aproveitamento deste material como substrato de fermentação na geração de gás metano, buscando valorizar essa biomassa que atualmente vem causando sérios danos ao meio ambiente. O trabalho contém estudos que avaliam e comparam as eficiências de produção de biogás e metano quando utilizados diferentes tipos de substratos buscando identificar a composição ideal para a biodigestão.

\section{Metodologia}

$\mathrm{O}$ trabalho experimental consistiu na investigação do potencial de metanização da E. crassipes.

Os experimentos foram divididos em duas etapas: na primeira fase do projeto foram avaliados os efeitos da adição de inóculo em meios de reação triturados e fluidizados. A segunda etapa consistiu-se em avaliar o desempenho da correção de $\mathrm{C} / \mathrm{N}$ e adição de carbonato como solução tampão em meio triturado inoculado.

\section{Instalações experimentais}

A pesquisa proposta foi desenvolvida no Laboratório de Química do Centro Universitário de Lins.

Para realização dos ensaios foram utilizados como bioreatores garrafas âmbar com volume de $600 \mathrm{~mL}$, comercialmente vendidas como embalagens de cerveja. Na tampa do reator foi utilizada uma rolha para vedar o sistema e acoplada uma mangueira para conduzir o biogás produzido até o sistema de coleta do gás, figura 1 .

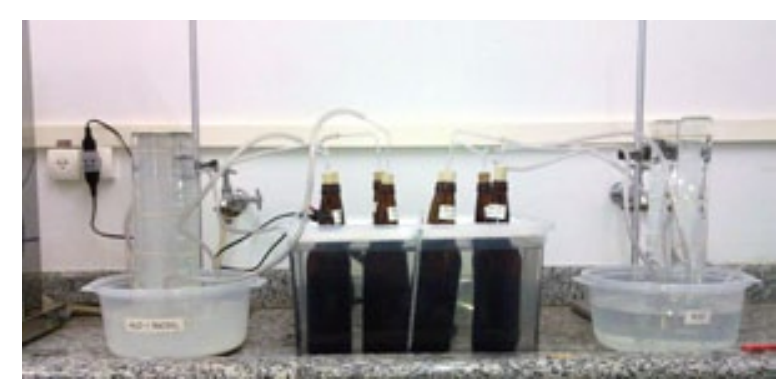

Figura 1 - Bancada experimental 
Os reatores foram mantidos a temperatura constante, $30^{\circ} \mathrm{C}$, para isso os mesmos foram instalados em um recipiente com água dotada de um termostato com aquecedor elétrico e uma bomba de agitação para a homogeneização da temperatura.

A produção do biogás foi registrada utilizando o método de deslocamento de volume utilizando provetas de $500 \mathrm{~mL}$ invertidas em um recipiente com água, figura 2. Para realizar a medição do gás metano, em um dos recipientes foi preparada uma solução com hidróxido de bário $(\mathrm{Ba}(\mathrm{OH}) 2)$, cujo objetivo foi dissolver o dióxido de carbono (CO2) presente no biogás, já que o mesmo é considerado como o principal problema na viabilização do armazenamento e na produção de energia, interferindo principalmente na qualidade do biogás.
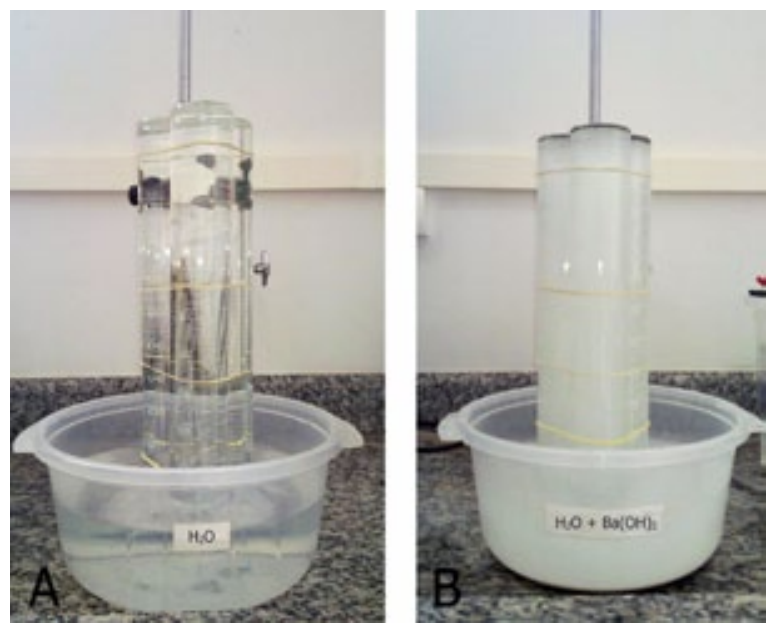

Figura 2 - Provetas empregadas como gasômetro: (A) proveta com água (B) proveta com solução de hidróxido de bário.

\section{Preparação do meio de reação}

Foram utilizados como substratos de fermentação as folhas, caules e as raízes da Eichhornia crassipes, provenientes do curso d'água urbano, o rio Dourado, localizado no Município de Lins, figura 3. Os aguapés coletados foram os que apresentaram diâmetro foliar entre $12 \mathrm{~cm}$ e 15 $\mathrm{cm}$, ou seja, se encontram na fase adulta, simulando a necessidade de limpeza das Wetlands e outras lagoas de tratamento de esgoto, já que os aguapés ao atingirem a fase adulta passam a reter menos nutrientes em seu tecido e devem ser descartados.

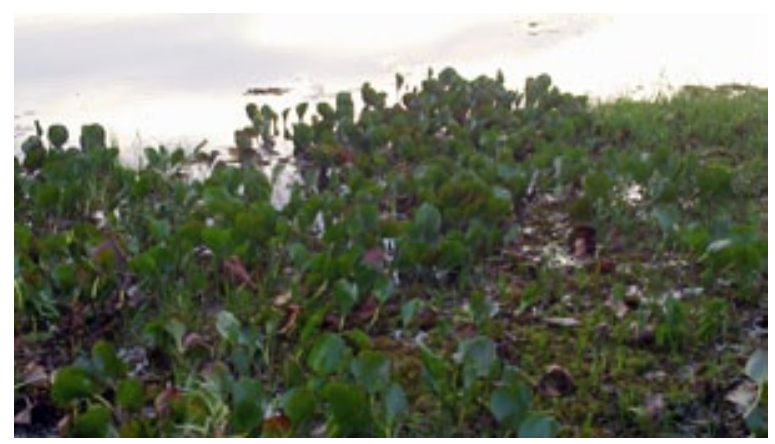

Figura 3 - Aguapé rio Dourado.

Após a realização da coleta em campo, o aguapé passou por um processo de esterilização com água sanitária e em seguida foram submetidas à cominuição.

Foi trabalhado com aguapé verde triturado de tamanho médio inferior a $3 \mathrm{~mm}$, feito por inspeção visual, e também foi realizado experimentos com o "suco" do aguapé.

Os volumes de trabalho em cada um dos diges-

\begin{tabular}{|c|c|c|c|c|c|c|c|c|}
\hline \multicolumn{4}{|c|}{ PRIMEIRA ETAPA } & \multicolumn{5}{|c|}{ SEGUNDA ETAPA } \\
\hline Experimento & Aguapé (g) & $\begin{array}{c}\text { “Suco" } \\
\text { aguapé (mL) }\end{array}$ & Inóculo $(\mathrm{mL})$ & Experimento & Aguapé (g) & Serragem (g) & $\begin{array}{l}\text { Inóculo } \\
\text { (mL) }\end{array}$ & $\begin{array}{c}\text { Bicarbona- } \\
\text { to (mL0 }\end{array}$ \\
\hline TH 0 & 170 & $--\cdot$ & $--\cdot$ & THT 25 (1) & 40 & $-\cdot$ & 22,6 & 0,25 \\
\hline TH 25 & 170 & $--\cdot$ & 128 & THT 25 (2) & 40 & $--\cdot$ & 22,6 & 0,90 \\
\hline SH 0 & --. & 260 & --. & THS 25 & 40 & 54,2 & 118,8 &.-- \\
\hline SH 25 & -.- & 260 & 96 & THTS 25 & 40 & 54,2 & 118,8 & --- \\
\hline TC 0 & 170 & $-\cdots$ & $--\cdot$ & TCT 25 (1) & 40 & $\cdots$ & 22,6 & 0,25 \\
\hline TC 25 & 170 & $--\cdot$ & 128 & TCT 25 (2) & 40 & $\cdots$ & 22,6 & 0,90 \\
\hline SC 0 & $\cdots$ & 260 & $--\cdot$ & TCS 25 & 40 & 54,2 & 118,8 & $--\cdot$ \\
\hline SC 25 & --- & 260 & 96 & TCHS 25 & 40 & 54,2 & 118,8 & $\cdots$ \\
\hline
\end{tabular}

Tabela 1 Informações dos substratos utilizados na digestão. 
tores se encontram na tabela 1 , a relação água biomassa utilizada foi de 2:4 e 4:5, respectivamente para o meio triturado e fluidizado na primeira etapa e 4:5 na segunda.

A correção do $\mathrm{pH}$ para aproximadamente 7 , foi feito através da adição da solução de Hidróxido de sódio $(\mathrm{NaOH})$ 0,1N, medido com papel indicador universal.

A determinação do teor de umidade para obtenção dos sólidos totais foi feita pelo Método Clássico, gravimetricamente, até obtenção da massa constante, conforme descrito pelo Instituto Adolf Lutz (2005), utilizando as seguintes equações:

$$
U=\left[\frac{(P U-P S)}{P U}\right] .100
$$

Onde:

U é o teor de umidade da amostra, em \%; Pu é o peso úmido da amostra, em g; e Ps é o peso seco da amostra, em $g$

$$
S T=100-U
$$

EQ. (2)

Onde:

ST é o teor de sólidos totais, em \%; e U é o teor de umidade da amostra, em \%, obtidos pela equação (1)

Já na determinação das concentrações de sólidos voláteis, os materiais já secos em estufa, foram levados a mufla a $550^{\circ} \mathrm{C}$ por $1 \mathrm{~h}$, esfriados em dessecador até atingirem peso constante, massa final de inertes (cinzas), e o teor de sólidos voláteis foi determinado utilizando a seguinte equação (3):

$$
S v=\left[\frac{\left(P_{S}-P_{m}\right)}{P_{S}}\right] \cdot 10
$$

EQ. (3)

Onde:

SV é o teor de sólidos voláteis, em \%; Pm é o peso obtido após a queima no bico de bunsen, em g; e Ps é o peso seco da amostra, em $g$
Antes de dar inicio ao experimento foi retirado o oxigênio presente nos reatores com o auxilio de uma chama, onde a combustão consumiu todo o oxigênio presente no interior dos mesmos e, em seguida, foram vedados com a rolha. Todo o sistema também foi coberto por um pano preto impedindo a luminosidade e assim garantindo a não realização da fotossíntese. Com isso foi proporcionado todas as condições necessárias para o inicio imediato da fermentação anaeróbia.

\section{RESULTADOS E DISCUSSÕES}

\section{Parâmetros físicos}

O teor de umidade, de sólidos totais e sólidos voláteis, verificados no inicio do experimento, são apresentados na tabela 2 , os resultados foram obtidos através de tripla amostragem para uma avaliação quantitativa correta.

\begin{tabular}{c|c|c|} 
Umidade (\%) & Sólidos totais (\%) & $\begin{array}{c}\text { Sólidos voláteis } \\
\text { (\%) }\end{array}$ \\
\hline 86,655 & 13,345 & 92,769 \\
\hline
\end{tabular}

Tabela 2- Caracterização da E. crassipes no inicio da digestão.

Analisando os dados da tabela 2, observa-se que o substrato foi constituído por apenas $13,34 \%$ de sólidos totais. Isto significa dizer que dos $170 \mathrm{mg}$ de substrato inicialmente utilizados para o abastecimento dos reatores, apenas 22,68 mg correspondia ao material sólido. Da fração de sólidos totais, 92,77\%, em média, era constituído de materiais sólidos voláteis, que apresentam possibilidade de ser mais facilmente digeridos.

\section{Resultados da primeira etapa experimental}

Os experimentos desta etapa foram monitorados por um período de 25 dias, sendo que as medições foram realizadas no inicio de hora em hora e passado às 6 horas iniciais de operação foi registrado a produção diária.

Nesta etapa todos os reatores apresentaram taxa de produção de metano inferior ao citado nas literaturas. Para o meio de reação com aguapé triturado não inoculado (TC 0) e inoculado (TC 25), respectivamente, a porcentagem de metano presente foi em torno de $16,67 \%$ e $24,24 \%$, 
apresentando um percentual volumétrico de gás metano pouco significativo, já que as concentrações de metano são usualmente na faixa de 55\% a 70\% (PINTO, 1999). Já para o meio de reação com "suco" de aguapé não foi possível estimar a porcentagem de metano presente no biogás devido à inversão da relação biogás e metano produzido, em que se alcançou uma maior produção de metano do que de biogás.

A baixa produção de metano pode ser explicada pelo $\mathrm{pH}$ final de cada substrato $(\mathrm{pH} 5)$, verificou-se faixas abaixo da atividade metanogênica, inibindo a ação das bactérias produtoras de metano. Esta redução pode ter sido provocada pela baixa relação $\mathrm{C} / \mathrm{N}$ dificultando a fermentação e o crescimento microbiano, pois a relação $\mathrm{C} / \mathrm{N}$ ideal está entre 25:1 e 30:1 (YADVIKA, et al., 2004), e para o experimento foi utilizado o aguapé como única fonte de carbono, que apresenta a relação $\mathrm{C} / \mathrm{N}$ na ordem de 8,9 , afetando assim o desenvolvimento principalmente das bactérias metanogênicas, pois elas são as mais sensíveis, ocasionando o acúmulo de ácidos voláteis, produzidos nas primeiras etapas da fermentação acima da capacidade de consumo das bactérias metanogênicas, acidificando o meio, ou então, pela incapacidade do meio em produzir solução tampão, geralmente bicarbonato, para manter o pH favorável a metanização.
Na figura 4 são mostrados os volumes acumulados de biogás e metano produzidos durante a primeira etapa experimental.

Pode observar que a adição de inóculo no meio fluidizado inibiu a etapa metanogênica, e no meio triturado, mesmo não interferindo no volume de biogás produzido, melhorou a qualidade do biogás, aumentando a produção de metano.

Esta inversão dos resultados, em que a adição de inóculo foi benéfica para o meio triturado e não benéfica para o meio fluidizado, podem ser explicadas pelas características de cada substrato, possivelmente, o meio composto por aguapé triturado ofereceu nutrientes suficientes para manter a massa microbiana, e a mesma, por sua vez, contribuiu na fase metanogênica, aumentando a produção, enquanto que no meio fluidizado, provavelmente, o inóculo utilizado não foi adequado para a degradação podendo ter desencadeado condição de competição devido à proliferação de microorganismos não desejados para o processo de metanização.

Resultados da segunda etapa experimental

Todos os reatores desta etapa foram inoculados, pois devido aos resultados obtidos na primeira etapa, se verificou uma melhora na qualidade do biogás com este procedimento, em que foram alcançados maiores produções de metano
Produção acumulada de Biogás $\left(\mathrm{cm}^{3}\right)$

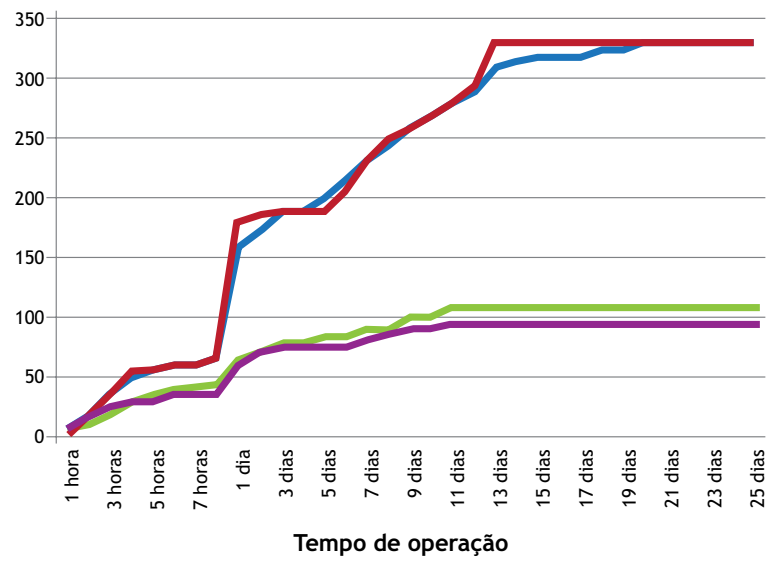

Produção acumulada de Metano $\left(\mathrm{cm}^{3}\right)$

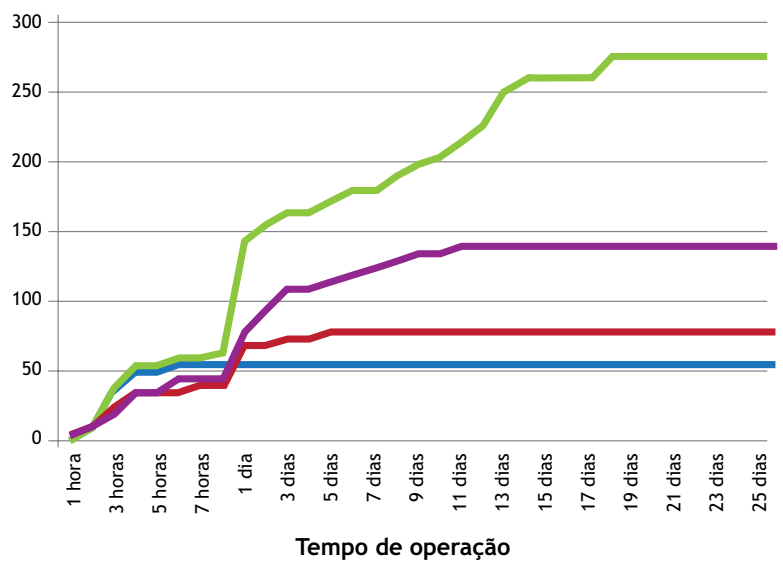

\begin{tabular}{ll|ll} 
TH 0 & TH 25 & SH 0 & SH 25
\end{tabular}

Figura 4- Produção acumulada de biogás e metano, em $\mathrm{cm}^{3}$, após o abastecimento dos reatores na primeira fase experimental 
no meio triturado inoculado.

Para a correção da relação $\mathrm{C} / \mathrm{N}$, elevando de 8,9 para 25 , atingindo a faixa ideal, como recomendado por (YADVIKA, et al., 2004), foi adicionado serragem junto às folhas, caules e raízes trituradas do aguapé. Foi adicionado também bicarbonato em alguns reatores para atuar como solução tampão, corrigindo assim todos os parâmetros necessários para se obter sucesso na digestão, principalmente na etapa metanogênica.

Após a inoculação o sistema foi monitorado diariamente por um período de 36 dias e as medições foram realizadas em intervalo de tempo igual à primeira etapa.

Na figura 5 são mostrados os resultados dos estudos em relação à produção acumulada de biogás e metano.

Analisando o perfil de produção de biogás e metano, verifica-se que o meio de reação onde foi apenas adicionado serragem (THS 25) apresentou uma taxa de degradação inferior aos demais. Este fato indica que, provavelmente, somente a correção da relação $\mathrm{C} / \mathrm{N}$, conforme determinado por (YADVIKA, et al., 2004), não foi suficiente para manter a estabilidade do $\mathrm{pH}$, indicando que o meio é incapacitado de produzir solução tampão, pois o $\mathrm{pH}$ final do substrato foi 5 , inibindo a atividade das bactérias metanogênicas.

Os maiores volumes de metano produzido fo- ram alcançados no reator com aguapé, serragem e bicarbonato (TCTS 25) e no reator onde foi adicionado 0,90 $\mathrm{mL}$ de bicarbonato (TCT 25(2)), respectivamente. Em ambos o pH se manteve estável, garantindo a eficiência na produção de metano pelas bactérias metanogênicas. $\mathrm{O}$ aumento da produção de metano, ocorrida no reator TCTS 25 , pode ser explicado pelo fato da correção $\mathrm{C} / \mathrm{N}$ beneficiar, principalmente, o desenvolvimento das bactérias metanogênicas alcançando assim maiores volumes de metano produzido.

No meio TCS 25 verifica-se uma produção quase que continua indicando que provavelmente não ocorreu a fase metanogênica. Já nos demais se percebe um salto na produção de metano, que provavelmente, indica inicio da fase metanogênica, principal responsável pela produção de metano.

Os reatores com a adição apenas de serragem (TCS 25) e com a adição de 0,25 mL de bicarbonato (TCT 25 (1)) apresentaram taxa de produção de metano inferior ao citado por Pinto (2009), com porcentagem de $8,69 \%$ e $34,71 \%$, respectivamente.

Os demais reatores apresentaram taxa de produção de metano satisfatória. No meio com serragem + bicarbonato (TCTS 25) a porcentagem foi de $80,76 \%$ e no meio com $0,90 \mathrm{~mL}$ de bicarbonato (TCT 25 (2)) foi de 56,12\%.
Produção acumulada de Biogás $\left(\mathrm{cm}^{3}\right)$

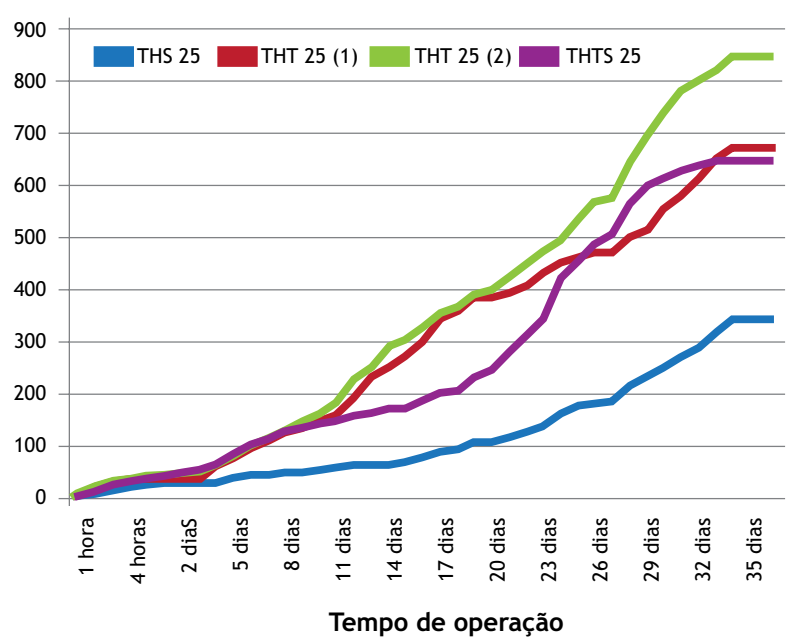

Produção acumulada de Metano $\left(\mathrm{cm}^{3}\right)$

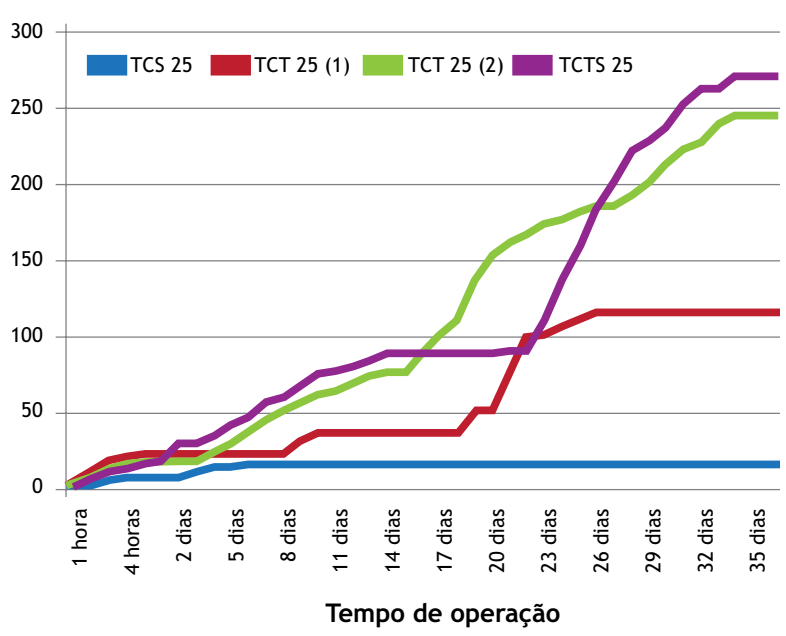

Figura 5- Produção acumulada de biogás e metano, em $\mathrm{cm}^{3}$, após o abastecimento dos reatores na segunda faze experimental. 


\section{CONCLUSÕES}

Com base nos resultados obtidos e na metodologia empregada pode-se chegar às seguintes conclusões:

De modo geral, a E. crassipes é recomendada para compor o substrato de metanização;

A adição de inóculo nos meios de reação com aguapé triturado não influenciou na quantidade de biogás gerado, no entanto, o meio inoculado apresentou maior produção de metano, ou seja, influenciou na melhora da qualidade do biogás produzido, sendo interessante sua utilização, pois de acordo com Costa (2006), seu poder calorífico aumenta de acordo com a quantidade de metano presente.

Em geral, os inóculos utilizados na pesquisa demonstraram que não influenciam na velocidade de degradação do aguapé, podendo indicar que o início da fase de metanogênica não depende do inóculo, ou então, a quantidade adicionada foi insignificante.

A correção apenas da relação $\mathrm{C} / \mathrm{N}$ não é suficiente para se atingir a faixa ideal de metanização, sendo necessária a adição de solução tampão.

Em geral, o sistema não é capaz de produzir solução tampão para manter a estabilidade do pH, sendo necessário a adição desta solução para a produção de biogás com concentrações considerável de metano.

O emprego de 25\% de inóculo, proveniente da lagoa anaeróbia da ETE, e uso de aguapé triturado mais serragem, para a correção C/N em 25, e a adição de bicarbonato conduziu a formação de biogás contendo 80,76\% de metano, atingindo de acordo com Costa (2006), poder calorífico entre $6.253,01$ e $10469,60 \mathrm{kcal} / \mathrm{kg}$, possibilitando a utilização deste resíduo para compor o substrato de metanização, e posterior seu aproveitamento energético.

Nas condições experimentais avaliadas, para o reator que apresentou maior produção de metano foi obtido rendimento em biogás de 6,90 $\mathrm{cm}^{3} / \mathrm{g}$ de substrato.

\section{AGRADECIMENTOS}

Aos professores de Engenharia Ambiental do Centro Universitário de Lins e aos funcionários do laboratório de química da Unilins pela ajuda e colaboração.

\section{REFERÊNCIAS}

CONNOR, S. Warning: Oil supplies are running out fast.. Jornal The Independent. Londres, 3 agosto 2009. Disponível em: <http://www.independent. co.uk/news/science/warning-oil-supplies-are-running-out-fast-1766585.html>. Acesso em 12 abril 2011.

COSTA, D.F. Geração de energia elétrica a partir do biogás do tratamento de esgoto. 2006. 194f. Dissertação (Mestrado em Energia), Universidade de São Paulo, São Paulo, 2006.

INSTITUTO ADOLFO LUTZ. Procedimentos e determinações gerais. In: Métodos físico-químicos para análise de alimentos, 4. ed., São Paulo:Imesp, cap. 4, p. 102-103, 2005.

KNIPLING, E. B. et al. Crowth characteristics, yield potential and nutritive content of Water Hyacinths. Soil Crop. Sci. Soc. of Florida proceedings, v. 30, p. 51-63, 1970.

MINISTÉRIO DA SAÚDE, IBGE. Caderno de informações de saúde. Brasília, 2010. Disponível em: $<\mathrm{ftp}$ ///ftp.datasus.gov.br/caderno/geral/br/Brasil_ GeralBR.xls > Acesso em: 26 de abril 2011.

MME; EPE. Balanço energético nacional 2010, Brasília, 2010. 276 p.

MUKUNO, D.R.O. et al. Efeito de fatores ambientais na morfologia das plantas de Aguapé. Revista Brasileira de Botânica. São Paulo, v. 8, p. 231-239, 1985.

PINTO, C.P. Tecnologia da digestão anaeróbia da vinhaça e desenvolvimento sustentável. 1999. 162 f. Dissertação (Mestre em Planejamento de Sistemas Energéticos) - Faculdade de Engenharia Mecânica, Universidade Estadual de Campinas, Campinas, 1999.

WOLVERTON, B. C.; MCDONALD, R. C. The water hyacinth from prolific pest to potencial provider. AMBIO, v.8, n. 1, 1979.

YADVIKA, S., SREECKRISHNAN, T. R., KOHLI, S., RANA, V. Ehnhancemente of biogas production from solid substrates using different tecniques-a review. Bioresource Tecnology, vol. 95, p.1-10. 2004 


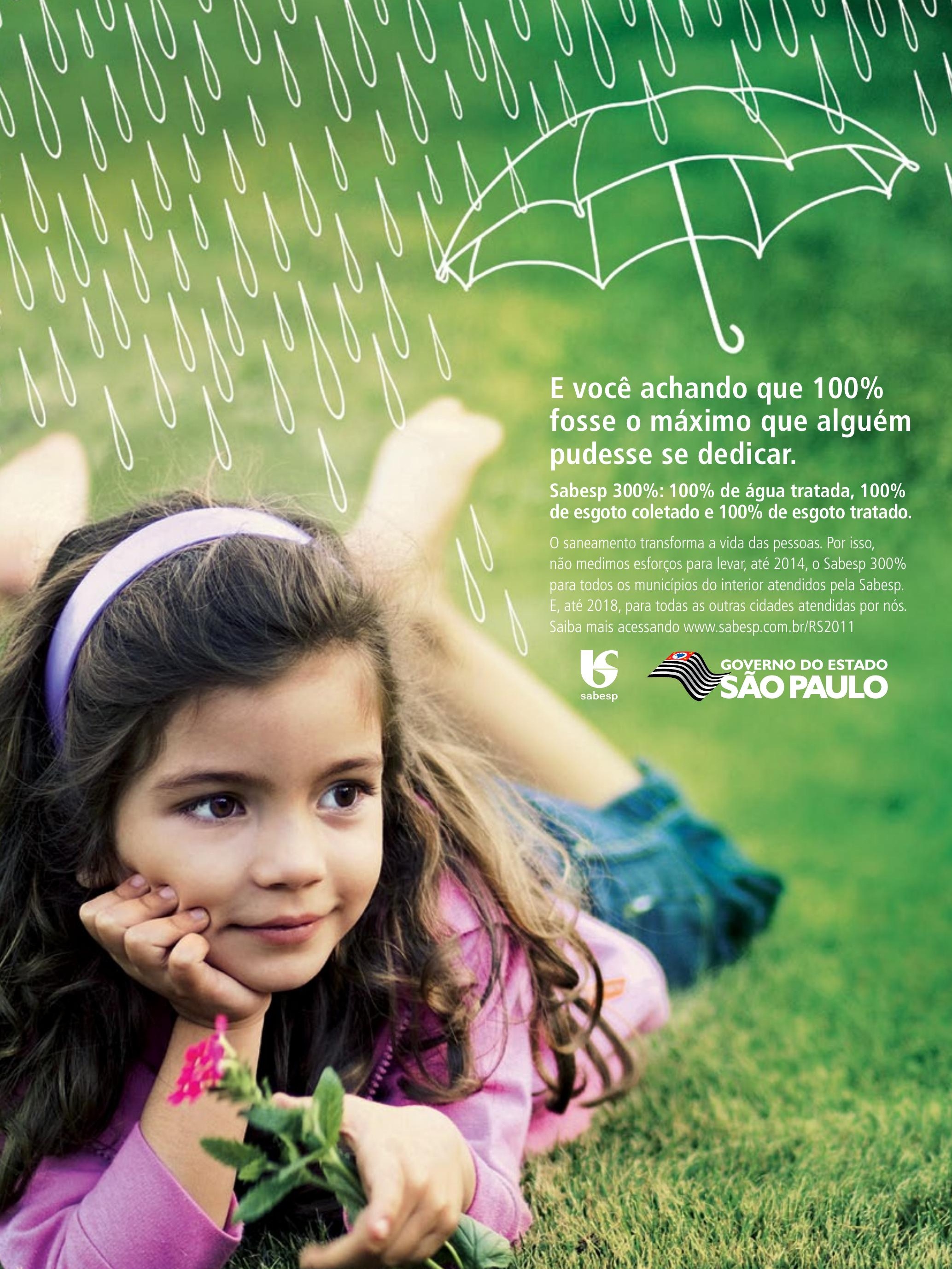

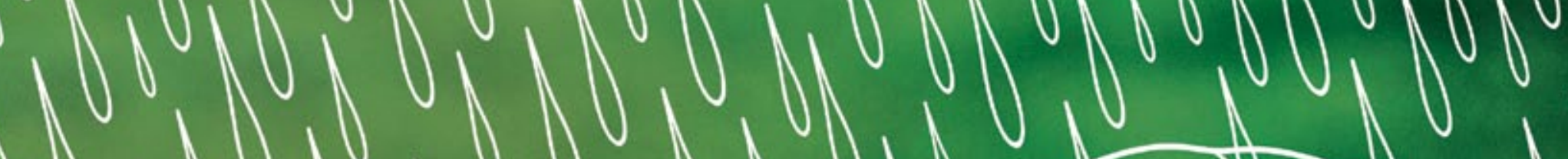

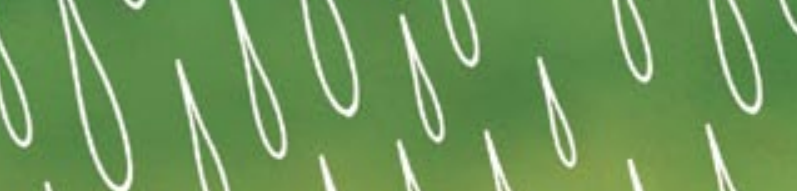
10100

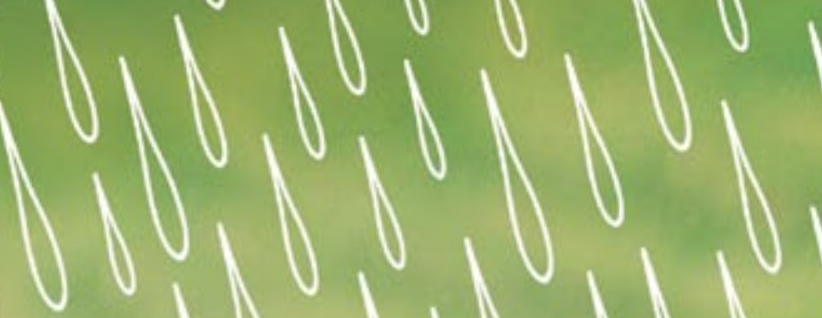

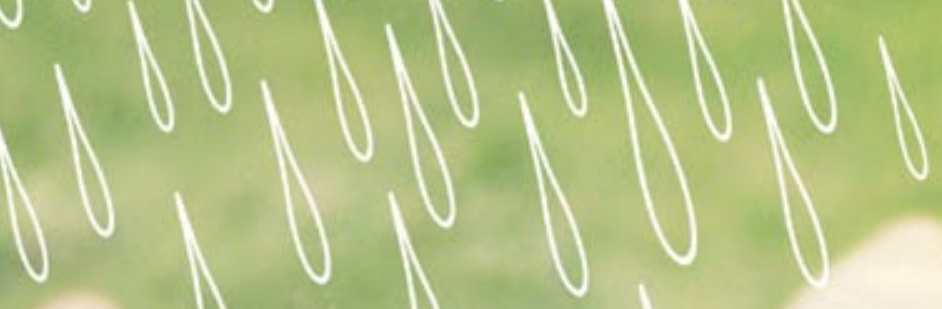

1

E você achando que $100 \%$ fosse o máximo que alguém pudesse se dedicar.

Sabesp 300\%: $100 \%$ de água tratada, $100 \%$

O saneamento transforma a vida das pessoas. Por isso,

não medimos esforços para levar, até 2014, o Sabesp 300\%

para todos os municípios do interior atendidos pela Sabesp.

E, até 2018, para todas as outras cidades atendidas por nós.

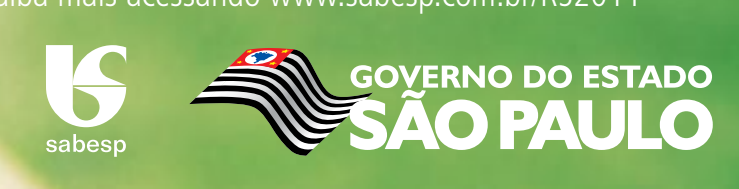

